handicap, discouraging people from enriching themselves and developing further. Many people in the periphery bear the burden of culture even more than the burdens of nature and natural habitat. Culture may be a home for them, but easily turns into a cosy prison.

As de Blij and others have pointed out, the world's poor are concentrated in the tropical latitudes. Here we have another paradox. The warm tropical latitudes are exceptionally rich in flora and fauna; by comparison, the deserts and middle latitudes are poor in plant and animal life. The same paradox seems to apply to culture. Take language and religion, for example; New Guinea has some 900 languages and subSaharan Africa has around 2,000; Europe, by contrast, is home to only about 200 languages.
The same disproportion is true of religion. Peoples in the tropics have many polytheistic belief systems in which they worship countless spirits and deities, and assign divine powers even to animals, plants and rocks. Peoples of the deserts and steppes, on the other hand, tend to be monotheistic, their belief systems simple and austere.

When we, members of the core, think of plants and animals, we always consider diversity to be a good thing and do our best to preserve it. This preference is sometimes carried over to human languages and cultures. Thus, like many other linguists of the core, de Blij laments the decline in the number of languages in tropical latitudes, forgetting that in New Guinea and Nigeria, the multiplicity of tongues is a barrier to the broad exchange of goods and ideas that is necessary for progress.

The Power of Place is full of fascinating facts, such as this one that I chose at random: global migration, large as it is, makes up less than $3 \%$ of the world's population. Despite de Blij's attempts, the mind still finds it hard to make sense of so much disparate information. He should have offered fewer facts, made a greater effort to subsume them under three or four linked concepts, and drawn simpler and stronger conclusions.

Yi-Fu Tuan is emeritus professor of geography at the University of Wisconsin-Madison, 550 North Park Street, Madison, Wisconsin 53706, USA.

His most recent book is Human Goodness.

e-mail: ytuan@geography.wisc.edu

\title{
A toolbox for policy planners
}

\author{
The Handbook of Technology Foresight \\ Edited by Luke Georghiou, Jennifer \\ Cassingena Harper, Michael Keenan, Ian \\ Miles and Rafael Popper \\ Edward Elgar: 2008. 456 pp. £115, \$220
}

During the past decade, many national governments have sponsored formal planning processes called technology foresight. Such exercises involve a wide range of stakeholders in anticipating long-term social, economic and technological developments, and then using the resulting vision to inform government policies. The growth of foresight activity, most prominently in Europe, reflects the desire of these governments to understand and influence today's rapid and profound social and economic changes, driven in large part by advances in technology and science.

The Handbook of Technology Foresight aims to shape this emerging field and to assist those planning foresight activities. Edited by five scholars active in foresight practice, the book opens with a critical review that defines and distinguishes foresight from other types of futures studies, alongside an excellent history of the field and a detailed summary of more than 30 methodologies. The second section surveys national foresight activities across Europe, Asia and the Americas, and the final section addresses common themes such as evaluation and policy transfer.

Initially a means of informing government investment priorities for research and development, the process of national technology foresight has expanded to address a full range of societal issues that affect and are affected by science and technology. The authors quote approvingly the definition of foresight given by the European Commission's FOREN project, which describes it as "a systematic, participatory, future-intelligence gathering and medium-to-long-term vision-building process aimed at present-day decisions and mobilizing joint actions". They name three characteristics that distinguish technology foresight from other approaches to futures studies. It looks to the future; it uses information about the future to inform near-term

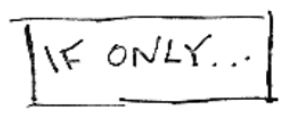

decisions; and it includes a broad range of individuals in group exercises to develop forecasts and explore their policy implications.

The book's survey of national programmes demonstrates that foresight activities are shaped by the particular needs, culture and politics of a country. The United Kingdom's foresight programme was established in 1993 and has become an institutionalized policy instrument for many agencies and departments. It uses a wide variety of methods such as scenarios, simulations and gaming, workshops and the Delphi interactive expert-based survey for forecasting. By contrast, the Japanese government's technology foresight programme, which has been running since 1969, carries out a nationwide Delphi survey of thousands of experts every five years to map out future developments in science and technology. Central and Eastern European countries have used technology foresight only sporadically, often hindered by political mindsets and institutional structures that are more at ease with single rather than multiple views of the

future, and with wholly separate government research endeavours rather than integrated national innovation systems.

Those considering a foresight exercise will find this book a valuable compendium that offers lessons to be learnt, and help in choosing goals, selecting methods and identifying successes and failures. Scholars will find a rich survey of current practice, methodological approaches and tensions in the field. But the book does not address the fundamental question of when national technology foresight can provide an appropriate means to achieve a society's goals.

Technology foresight aims to create a 'national public good'. At a time of fastpaced radical change, it seeks to offer a
Foresight in hindsight. (From 101 Funny Things About Global Warming by Sidney Harris and Colleagues; Bloomsbury, 2008.) 
commonly shared vision of the future and to create new networks that enable a society to invest its science and technology resources more wisely, harness the beneficial effects of innovation, and ameliorate its risks. Yet foresight may provide only one way to create these benefits. As the book describes, the French government sponsors a small number of comprehensive foresight activities. By contrast, in the United States, many groups - from the independent but government-funded National Academy of Sciences to numerous non-profit organizations - offer visions of the future and build networks around them. Clearly, these approaches reflect different political and cultural contexts. But the different visions may provide different strengths and weaknesses, for instance, offering coherent actions versus resilience to surprise. The book helps frame questions about, for example, which approaches governments should choose, but it does not answer such questions.

To call this volume a handbook may be premature. The word connotes an easily consulted reference that provides quick answers to those engaged in an activity. As the editors note, technology foresight remains a diverse and experimental practice whose theoretical foundations are poorly understood and whose successes have not yet moved from the anecdotal to the empirically grounded. Much remains to be learned. Meanwhile, The Handbook of Technology Foresight provides an important survey of current knowledge that will help governments use foresight to navigate these tumultuous times. Robert Lempert is director of the RAND Frederick S. Pardee Center for Longer Range Global Policy and the Future Human Condition, 1776 Main Street, Santa Monica, California 90401, USA.

e-mail: lempert@rand.org

\section{Potatoes and poverty}

\section{Propitious Esculent: The Potato in \\ World History \\ by John Reader \\ William Heinemann: 2008. 315 pp. £18.99}

Propitious Esculent is not just a book about potatoes; it is also about poverty. The two are linked by history, and in this very readable account, anthropologist and journalist John Reader shows us how.

The cultivated potato, Solanum tuberosum, is one of around 1,500 species in the flowering plant genus Solanum, which also includes the tomato, aubergine and woody nightshade. There are some 190 species of wild potatoes, all found in the Andes - from these a single species has been domesticated and spread throughout the world. Those who only see potatoes in heaps at supermarkets may be surprised that the crop comes from a flowering plant and is one of South America's greatest contributions to the European diet. The United Nations Food and Agriculture Organization has declared 2008 the International Year of the Potato to raise awareness of its importance.

Botanically, the potato is a tuber, a swollen piece of underground stem where the plant stores starch. Wild potato plants and local 'primitive' varieties have tubers, but they are often small and oddly shaped, bearing little physical resemblance to those from cultivated varieties. Reader cites recent research on the taxonomy and domestication of these varied and complicated plants. Disappointingly, he does not incorporate recent work on the genetics of the potato and its relatives.

Nor does the book sufficiently discuss the genetic modification of potatoes for control of disease, an important issue for food poverty. Potatoes are one of the most expensive food crops in terms of pest and disease control. Reader cites the potato as the "world's most chemically dependent crop - with the global cost of fungicides standing at [US] $\$ 2$ billion per year". This astounding figure comes almost as a footnote at the end of a long chapter about the discovery of Phytophthora infestans, the agent of potato blight. The fungus, now associated with the devastation of world potato crops, was first discovered in grapevines. Reader's account of the disease, its discovery and its action is riveting, but potatoes are almost incidental to his story. Today, we easily see the connection between symptom and disease and can then search for causative agents: this was not so in the days when people thought microorganisms arose from spontaneous generation.

Reader does detail the development of blight-resistant potato varieties through the plant-breeding work of Redcliffe N. Salaman at the University of Cambridge, UK, in the early twentieth century. But he does not discuss more modern and controversial approaches. Disease control is being developed at the International Potato Center in Peru through 'true potato seed' potatoes - the crop is replanted using the seed from the original potato plant rather than vegetatively propagated from small pieces of tuber. These varieties have great promise for improving the gene pool for disease resistance, especially in the Andes, where genetically engineered potatoes cannot be used because of their potential for hybridizing with wild species.

Reader eloquently argues that social history is important to understand agricultural systems and sustainability. His engaging account of the potato's journey, from the Andes to Europe and beyond, starts and ends in local communities where the tuber is still central to daily life. Andean cultures cultivate potatoes in poorquality soils at high altitudes, mainly because

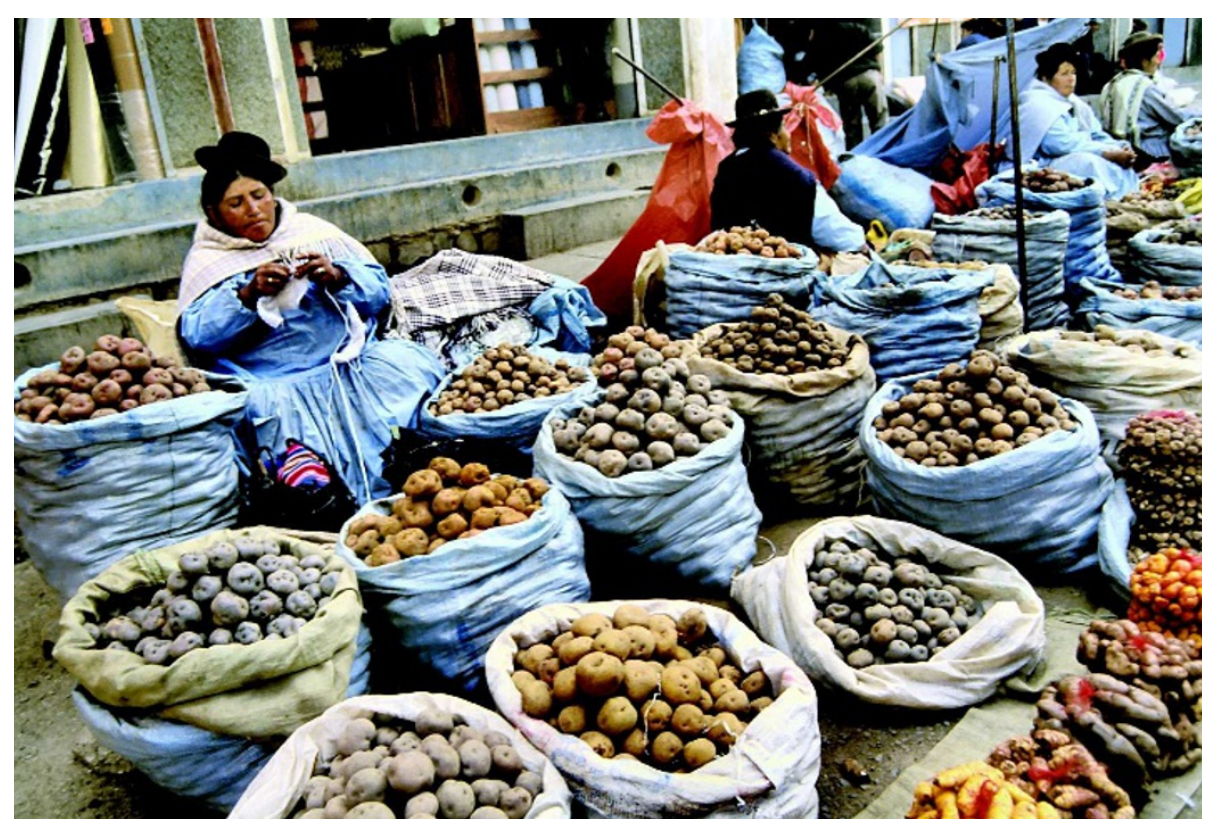

Mash production: potatoes are the world's most chemically dependent crop. 